\title{
Venlafaxine intoxication in an adolescent presenting with severe lactic acidosis
}

\author{
İrem Eldem ${ }^{1}$, Tanıl Kendirli², Ebru Azapağası², Gülşah Özdemir ${ }^{1}$, Çisem Yıldız \\ Mehmet Mustafa Yılmaz ${ }^{1}$, Özlem Karataşoğlư ${ }^{1}$, Elif Benderlioğlu ${ }^{1}$ \\ ${ }^{2}$ Pediatric Intensive Care Unit, ${ }^{1}$ Department of Pediatrics, Ankara University Faculty of Medicine, Ankara, Turkey. \\ E-mail: irem.eldem@gmail.com \\ Received: 3 June 2015, Revised: 29 September 2015, Accepted: 18 November 2015
}

\begin{abstract}
SUMMARY: Eldem İ, Kendirli T, Azapağası E, Özdemir G, Yıldız Ç, Yılmaz MM, Karataşoğlu Ö, Benderlioğlu E. Venlafaxine intoxication in an adolescent presenting with severe lactic acidosis. Turk J Pediatr 2016; 58: 200-202.

Venlafaxine is a selective serotonin noradrenaline reuptake inhibitor and commonly prescribed antidepressant in adults. Most patients overdosing with venlafaxine develop only mild symptoms. Severe toxicity is reported with the most common symptoms being CNS depression, serotonin toxicity, seizure, or cardiac conduction abnormalities. However, lactic acidosis is an uncommon adverse effect. Here, we present the first case in the literature reporting lactic acidosis due to venlafaxine overuse in an adolescent.
\end{abstract}

Key words: venlafaxine, overdose, lactic acidosis, adolescent.

The widely used venlafaxine is an antidepressant that inhibits neuronal reuptake of serotonin, noradrenaline and dopamine. It has a rather high fatal toxicity index in comparison with serotonin reuptake inhibitors (SSRIs) ${ }^{1}$. It is known that doses of $900 \mathrm{mg}$ or more are likely to cause moderate toxicity and there is no official therapeutic dose recommendation in children ${ }^{2}$. Cardiovascular and neurological toxicities are widely known outcomes of venlafaxine overdose. A single case of lactic acidosis attributed to venlafaxine intoxication was published in an adult patient ${ }^{3}$. Here, we report the first child case in the literature that is a 17-year-old girl who presented with lethargy and lactic acidosis due to venlafaxine intoxication.

\section{Case Report}

A 17-year-old girl with no significant medical history was brought to the pediatric emergency department after overdose with venlafaxine. The patient had attempted suicide about one hour before presentation. She ingested 26 extended-release $150 \mathrm{mg}$ capsules of venlafaxine belong to her grandfather under the therapy of colon cancer. The total ingested dose was approximately $3900 \mathrm{mg}$. She had not taken any other medications or alcohol. At the time of presentation, she did not have any complaints. She was hemodynamically stable with blood pressure 100/60 $\mathrm{mm} \mathrm{Hg}$ and pulse rate of $100 \mathrm{bpm}$. Body temperature was $37.5^{\circ} \mathrm{C}$. Cardiovascular and respiratory systems were normal. Her initial Glasgow Coma Score was 15. Complete blood count, liver and kidney function tests were normal. The initial management was done with gastric lavage and oral activated charcoal. During follow up she had tachycardic (pulse rate: $140 \mathrm{bpm}$ ) and ECG showed that it was sinus tachycardia.

After four hours from admission, a change in her consciousness occurred. She was somnolent and disoriented with a Glasgow Coma Score of 9 (V2-E3-M4). Her vital signs were still stable except sinus tachycardia. The physical examination of peripheral perfusion and blood pressure was normal. The blood glucose was $126 \mathrm{mg} / \mathrm{dl}$. Although she had altered mental status, the other symptoms of excessive serotonergic activity such as hyperthermia, clonus, muscle rigidity or tremor were absent. She transferred to our intensive care unit and arterial blood gas revealed $\mathrm{pH} 6.97, \mathrm{PCO}_{2} 22.7$ $\mathrm{mm} \mathrm{Hg}, \mathrm{PO}_{2} 128 \mathrm{~mm} \mathrm{Hg}, \mathrm{HCO}_{3} 3 \mathrm{mmol} / \mathrm{L}$, $\mathrm{BE}-21 \mathrm{mmol} / \mathrm{L}$, lactate $16 \mathrm{mmol} / \mathrm{L}$, and anion gap 33. Control blood gas after 15 minutes was also consistent with severe metabolic lactic 
acidosis: $\mathrm{pH} 7.19, \mathrm{PCO}_{2} 34 \mathrm{~mm} \mathrm{Hg} \mathrm{HCO}_{3} 13.7$ $\mathrm{mmol} / \mathrm{L}, \mathrm{BE}-14 \mathrm{mmol} / \mathrm{L}$, lactate $13 \mathrm{mmol} / \mathrm{L}$. We gave oxygen therapy with a face mask. Deficit with normal saline from $20 \mathrm{ml} / \mathrm{kg}$ was given within one hour and intravenous maintenance fluid was continued. After two hours, the blood gas was completely normal. Glasgow score progressively improved within 4 hours. The patient was discharged after 24 hours without sequelae and consulted to the child psychiatry department due to the suicide commitment.

\section{Discussion}

In our patient, sedation, tachycardia and lactic acidosis were observed after high dose venlafaxine ingestion. Venlafaxine is a bicyclic phenyl and ethylamine derivative, which received FDA approval as an antidepressant in 1994. It was observed that venlafaxine blocks the reuptake of norepinephrine, serotonin and weakly dopamine. Thus it can be described as a serotonin-norepinephrine reuptake inhibitor (SNRI). Venlafaxine is extensively metabolised in the liver after oral intake by cytochrome P450 enzyme system. The half life of the extended-release formulation of venlafaxine is approximately five hours and eliminated through kidneys. It is licensed for the treatment of depression, general anxiety disorder and social anxiety in adults. It is not approved in pediatric usage; but studies yielded promising results in children and adolescents with depression, attention deficit and hyperactivity, autism spectrum and conduct disorders ${ }^{2}$.

Because of its more selective biochemical activity, venlafaxine is as effective as tricyclic antidepressants (TCA) but associated with fewer anticholinergic, central nervous system and cardiac side effects ${ }^{4}$. Most patients develop mild symptoms with venlafaxine overdose. The most common adverse effects of venlafaxine in children and adolescents include nausea, vomiting, abdominal pain, headache, drowsiness, insomnia, restlessness, irritability, dizziness, anorexia and increased appetite. On the other hand, fatal adverse effects such as central nervous system depression requiring intubation, generalized seizures, and serotonin syndrome may occur ${ }^{5}$. Cardiac toxicity (QTc interval prolongation, cardiac arrythmia, hypertension, hypotension) serotonergic mediated toxic effects (altered mental status, neuromuscular abnormalities and autonomic dysfunction), hypoglycemia and lactic acidosis were reported to be seen in venlafaxine toxicity in adult and few pediatric cases ${ }^{6-9}$.

Approximately $20 \mathrm{mmol}$ of lactate per kilogram of body weight is produced in the human body daily, primarily by glycolysis and is catalyzed by lactate dehydrogenase (LDH) in the cytosol (Fig. 1). Lactic acidosis occurs when lactate production exceeds lactate consumption, marked by plasma lactate concentration $\geq 5$ $\mathrm{mmol} / \mathrm{L}$. Lactic acidosis can be caused by tissue hypoxia that result in lactate overproduction and underutilization as a result of impaired mitochondrial oxidation. It can also result from aerobic glycolysis which referred as stimulated glycolysis that depends on factors other than tissue hypoxia. Disorders associated with elevated epinephrine levels such as severe asthma, extensive trauma, cardiogenic or hemorrhagic shock and pheochromocytoma can cause lactic acidosis through this mechanism. Reduced clearance and increased production of lactate in liver disease can cause lactic acidosis. Drugs that impair oxidative phosphorylation, such as antiretroviral agents, metformin and propofol can also lead lactic acidosis. Overall, lactic acidosis impairs cellular functions and tissue perfusion ${ }^{10,11}$.

Drug induced lactic acidosis has been hypothesized to be due to mitochondrial DNA damage and subsequent mitochondrial dysfunction leading to increase in glycolysis and lactate production. Metformin is more often used in pediatric patients than venlafaxine and

\section{Glucose (Cytosol: anaerobic glycolysis)}

$2(A D P+P i)$

2 ATP
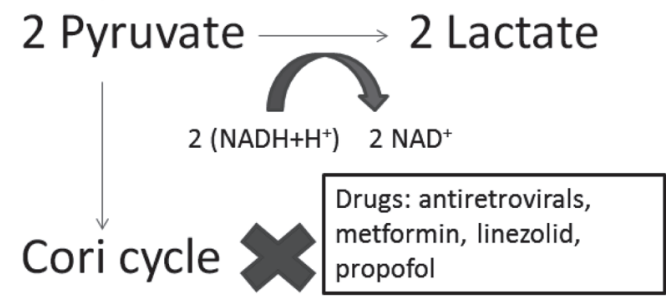

(Mitochondrion: oxidative phosphorylation)

Fig. 1. Lactate synthesis and lactic acidosis caused by drugs 
its most serious side effect is lactic acidosis. Metformin raises lactic acid levels by promoting anaerobic metabolism and interferes with complex 1 of the respiratory chain, leading to an inhibition of mitochondrial respiration ${ }^{12}$.

Venlafaxine selectively inhibits the reuptake of norepinephrine. As previously mentioned above, disorders associated with elevated epinephrine levels stimulate the $\beta_{2-\text { adrenoceptor which }}$ augments the glycolysis. This can be another factor for lactic acidosis caused by venlafaxine.

This case of venlafaxine associated lactic acidosis was treated with activated oral charcoal, oxygen and intravenous fluids. An adult case of lactic acidosis attributed to venlafaxine overdose was reported in a 55 -year-old patient ${ }^{3}$. The patient had attempted suicide by ingestion of 6,000 mg of venlafaxine. In contrast to our patient, he was anxious, tachycardic and tachypneic at first presentation. His blood tests were normal except lactic acidosis. Lactic acidosis resolved after 16 hours from admission with aggressive intravenous hydration along with activated charcoal. Our patient ingested a lower dose of venlafaxine. Tachycardia which is observed in venlafaxine overdose was resolved the other day. Oxygen and IV fluids were given to support hemodynamic status, as severe lactic acidosis may deteriorate the patient. Bicarbonate could be given; but the blood gas showed marked improvement quickly with supportive therapy. No specific antidotes are known and due to large distribution of volume of venlafaxine; forced diuresis, dialysis, hemoperfusion and exchange transfusion are of no benefit.

We suggest that the quick clinical response may be attributed to higher rate of drug metabolism at younger ages. Furthermore, due to genetic polymorphisms in cytochrome P450 enzyme, the metabolism of venlafaxine varies between patients ${ }^{2}$.

In conclusion, our case serves to illustrate some rare consequences of venlafaxine overdose, such as mental status change and lactic acidosis in an adolescent. Mental status change is a part of serotonin syndrome, which is a well known adverse effect of venlafaxine. However, physicians should be aware of lactic acidosis which can complicate the clinical picture. In our case, early diagnosis and supportive therapy improved the clinical outcome of the patient; but new case reports are necessary.

\section{REFERENCES}

1. Hawton K, Bergen H, Simkin S, et al. Toxicity of antidepressants: rates of suicide relative to prescribing and nonfatal overdose. Br J Psychiatry 2010; 196: 354358.

2. Weller EB, Weller RA, Davis GP. Use of venlafaxine in children and adolescents: a review of current literature. Depress Anxiety 2000; 12(Suppl 1): 85-89.

3. Iragavarapu C, Gupta T, Chugh SS, Aronow WS, Frishman WH. Type B lactic acidosis associated with venlafaxine overdose. Am J Ther 2016; 23: e1082-e1084.

4. Kent JM. SNaRIs, NaSSAs, and NaRIs: New agents for the treatment of depression. Lancet 2000; 355: 911-918.

5. Taurines R, Gerlach M, Warnke A, Thome J, Wewetzer C. Pharmacotherapy in depressed children and adolescents. World J Biol Psychiatry 2011; 12 (Suppl 1): 11-15.

6. Francino MC, Deguigne MB, Badin J, Turcant A, Perrotin D. Hypoglycemia: a little known effect of Venlafaxine overdose. Clin Toxicol (Phila) 2012; 50: 215-217.

7. Hanekamp BB, Zijlstra JG, Tulleken JE, Ligtenberg JJ, van der Werf TS, Hofstra LS. Serotonin syndrome and rhabdomyolysis in venlafaxine poisoning: a case report. Neth J Med 2005; 63: 316-318.

8. Fischer M, Untrecker S, Pfuhlmann B. Overdose of venlafaxine with mild outcome. Neuroscience \& Medicine 2012; 3: 327-329.

9. Woodhouse B, Erramouspe J. Accidental ingestion of venlafaxine in a 9 month old infant. The Internet Journal of Toxicology 2012; 8: 1-4.

10. Kraut JA, Madias NE. Lactic Acidosis. N Engl J Med 2014; 371: 2309-2319.

11. Murphy ND, Kodakat SK, Wendon JA, et al. Liver and intestinal lactate metabolism in patients with acute hepatic failure undergoing liver transplantation. Crit Care Med 2001; 29: 2111-2118.

12. Owen MR, Doran E, Halestrap AP. Evidence that metformin exerts its anti-diabetic effects through inhibition of complex 1 of the mitochondrial respiratory chain. Biochem J 2000; 348: 607-614. 